African Journal of Biomedical Research, Vol. 9 (2006); 189 - 197

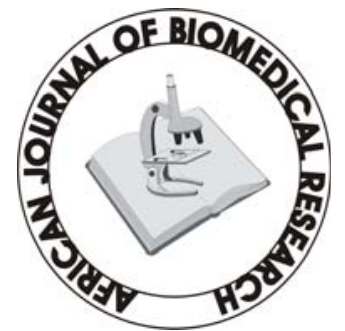

Full-text available at http://www.ajbrui.com http://www.bioline.br/md http://www.ajol.com

Received:

March 2006

Accepted (Revised):

August 2006

Published

September 2006
Full Length Research Article

\section{Effect of T. Arjuna Stem Bark Extract on Histopathology of Liver, Kidney and Pancreas of Alloxan-Induced Diabetic Rats}

\author{
${ }^{1}$ Ragavan, B., ${ }^{2}$ Krishnakumari.S \\ 1 PSG College of Arts and Science, \\ Coimbatore, Tamilnadu, India \\ 2 Kongunadu Arts and Science College, \\ Coimbatore, Tamilnadu, India
}

\begin{abstract}
The present study examined the effect of ethanolic extract (250 and $500 \mathrm{mg} / \mathrm{kg}$ body weight) of Terminalia arjuna stem bark in alloxan - induced diabetic rats for 30 days, and its histopathological study was investigated in the liver, kidney and pancreatic tissues sections. Pathological lesions were evoked in cells of diabetic rats. The extract improve the liver, kidney and pancreas function and reduce lesions associated with diabetic state in alloxan induced rats. The effect of oral administration of T. arjuna at a dose of $500 \mathrm{mg} / \mathrm{kg}$ body weight was more efficacy than the $250 \mathrm{mg} / \mathrm{kg}$ body weight. The results indicate the extract exhibit the protective effect on tissues, and proves its potentials as an antidiabetic agent. (Afr. J. Biomed. Res. 9: 189 - 197)
\end{abstract}

Keywords: Teminalia arjuna, histopathology, $\beta$ - cell, lesions, alloxan

*Address for Correspondence (e-mail) : ragav_psg@yahoo.co.in, Tel: 0422 - 2667916(Res); 0422 - 5397901 (Off)

Abstracted by:

African Index Medicus (WHO), CAB Abstracts, Index Copernicus, Global Health Abstracts, Asian Science Index, Index Veterinarius, Bioline International , African Journals online 


\section{INTRODUCTION}

In modern medicine no satisfactory effective therapy is still available to cure diabetes mellitus, which is a syndrome resulting from a variable interaction of hereditory and environmental factors and characterized by abnormal insulin secretion or insulin receptor or post - receptor events affecting metabolism involving carbohydrates, proteins and fats in addition to damaging $\beta$-cells of pancreas, liver and kidney in some cases (Ghosh, 2001). Patients depend on insulin for management of IDDM. Without insulin, they develop degenerative complications such as microangiopathy, nephropathy and retinopathy. Diabetic nephropathy is the most important cause of death in type 1 diabetic patients, of whom, $30-40 \%$ eventually develop end stage renal failure (Giorgino et al., 2004). Liver disease is one of the leading cause of death in persons with type 2 diabetes. The standardized mortality rate for death from liver disease is greater than that of cardiovascular disease. The spectrum of liver disease in type 2 diabetes ranges from nonalcoholic fatty liver disease to cirrhosis and hepatocellular carcinoma (Keith et al., 2004).

Experimental type 1 diabetes induced with streptozotcin or alloxan in rats display many features seen in human subjects with uncontrolled diabetes mellitus(Chattopadhyay et al ., 1997).

Terminalia arjuna belongs to the family Combretacea, (Roxb Wight Arn) is a large evergreen tree. The tree is found throughout Indian subcontinent, Myanmar, and Sri Lanka particularly in topical moist deciduous and dry deciduous forest. Naturally arjun favours river banks and the sides of water bodies (Purohi et al.,2004).The bark has been used in Indian native Ayurvedic medicine for over three centuries, primarily as a cardiotonic. Clinical evolution of this botanical medicine indicates it can be of benefit in the treatment of coronary disease, heart failure, and possibly hypercholestrolemia has been widely reported (Tiwari et al., 1989, Pathak et al., 1990, Khanna et al., 1996, Shaila et al., 1997a and Ram et al., 1997).

The importance of using herbal medicine in treating various diseases like diabetes mellitus looks lucurative. Meagre work has been done in T. arjuna on diabetes mellitus and histopathological studies. On the same line I have chosen such a wide medicinal characteristics plant $T$. arjuna stem bark extract in alloxan-induced diabetes. Focusing their abilities on the tissues protective effects.

\section{MATERIALS AND METHODS}

\section{Plant material and preparation of $50 \%$ ethanolic extract}

The wet Terminalia arjuna bark were collected from Siruvani coastel of Agali in Kerala, during september 2003 and were carefully identified and certified by Botanical survey of India (BSI) Coimbatore.

Terminalia arjuna was used in the form of crude $50 \%$ ethanolic extract and this extract was prepared according to the traditional system of medicine. The shade dried and coarsely powdered stem bark $(1 \mathrm{~kg})$ was extracted with 50\% ethanol (1.5L) in the cold for 72 hours. The extract was filtered and distilled on water bath, a reddish brown syrupy mass was obtained and it was finally dried at low temperature under reduced pressure in a rotary evaporator. A crude residue $(75 \mathrm{~g})$ was obtained giving a yield of $7.5 \%$. When needed, the crude extract was suspended in distilled water and used in the study.

\section{Animals}

Male albino rats of Wistar strain weighing about 150 - 200 g obtained from the Medical College of Trichur (Kerala) were used for the study. They were fed a standard rat pellet diet (Sai Durga feeds, Bangalore) and water was provided adlibitum and maintained under standard laboratory conditions. (Temperature $24-28^{\circ} \mathrm{C}$, relative humidity 60 - 70\%) Animal described as fasted were deprived of food for $16 \mathrm{~h}$ but had free access to water. Ethical clearance for the handling of experimental animals was obtained from the committee constituted for the purpose. (CPCSEANO: 659/02/a).

\section{Alloxan induced diabetes}

Diabetes was induced by a single ip injection of $120 \mathrm{mg} / \mathrm{kg}$ of alloxan monohydrate (S.D FineChe. Ltd., Mumbai, India), in sterile saline (Ravivijayavargia et al.,2003). After 72 hours of 
alloxan injection, the diabetic rats (glucose level> $250 \mathrm{mg} / \mathrm{dl}$ ) were separated and used for the study (Perfumi et al.,1996).

\section{Administration of plant extract}

The animals were divided in to 6 groups of 6 each. Group I served as normal healthy control. Group II (untreated diabetic control). Group III diabetic rats given T.arjuna bark extract $(250 \mathrm{mg} / \mathrm{kg}$ body weight). Group IV diabetic rats given T.arjuna bark extract (500 mg/kg body weight). Group V control rat given T.arjuna bark extract (250 mg/kg body weight) Group VI control rats given T.arjuna bark extract (500 mg/kg body weight). The drug was administered for the period of 30 days.

\section{Collection of blood liver kidney and pancreas}

After the experimental regimen, the animals were sacrificed by cervical dislocation under mild chloroform anesthesia. Blood was collected on decapitation and serum was separated by centrifugation. The kidney and liver were excised immediately and thoroughly washed in ice - cold saline. The serum and tissues were collected and used for biochemical experiments.

\section{Estimation of biochemical parameters}

Serum glucose was measured by GOD / POD method (Trinder 1969).

\section{Histopathology}

The liver, kidney and pancreas were preserved in $20 \%$ formalin immediately after removal from the animal.

\section{Tissue processing}

Liver, kidney and pancreatic tissues were placed in $10 \%$ formalin (diluted to $10 \%$ with normal saline) for $1 \mathrm{hr}$ to rectify shrinkage due to high concentration of formalin. The tissues were dehydrated by ascending grades of isopropyl alcohol by immersing in $80 \%$ isopropanol overnight and $100 \%$ isopropyl alcohol for 1 hour. The dehydrated tissues were cleared in two changes of xylene, 1 hour each. The wax impregnated tissues were embedded in paraffin blocks using the same grade wax. The paraffin blocks were morented and cut with rotary microtome at 3 micron thickness. The sections were floated on a tissue floatation bath at $40^{\circ} \mathrm{C}$ and taken on glass slides and smeared with equal parts of egg albumin and glycerol. The sections were then melted in an incubator at $60^{\circ} \mathrm{C}$ and after $5 \mathrm{~min}$ the sections were allowed to cool.

\section{Tissue staining}

The sections were deparaffinised by immersing in xylene for $10 \mathrm{~min}$ in horizontal staining jar. The deparaffinised sectons were washed in 100\% isopropyl alcohol and stained in Ehrlich's hematoxylin for $8 \mathrm{~min}$ in horizontal staining jar. After staining in hematoxylin, the sections were washed in tap water and dipped in acid alcohol to remove excess stain $(8.3 \% \mathrm{HCl}$ in $70 \%$ alcohol). The sections were then placed in running tap water for $10 \mathrm{~min}$ for blueing (slow alkalization). The sections were counter stained in $1 \%$ aqueous eosin (1 gm in $100 \mathrm{ml}$ tapwater) for $1 \mathrm{~min}$ and the excess stain was washed in tap water and the sections were allowed to dry. Complete dehydration of stained sections was ensured by placing the sections in the incubator at $60^{\circ} \mathrm{C}$ for $5 \mathrm{~min}$. When the sections were cooled, they were mounted in DPX mount having the optical index of glass (the sections were wetted in xylene and inverted on to the mount and placed on the cover slip).

The architecture was observed low power objective under microscope. The cell injury and over aspects were observed under high power dry objective (Dunn 1974).

\section{Statistical evaluation \\ Statistical evaluation was done using one- way analysis of variance (ANOVA) followed, by Duncan's Multiple Range Test (DMRT). Statistical significance was set at $(\mathrm{P}<0.05)$.}

\section{RESULTS}

\section{Effect of Terminalia arjuna (ethanalic extract) on serum glucose.}

The levels of glucose in serum, of alloxan induced diabetic rats were significantly $(\mathrm{p}<0.05)$ elevated as compared with control rats. Oral administration of $T$. arjuna (250 and 500mg/ kg body weight) to diabetic rats for 30 days caused significant reduction in serum glucose level (Table 1 ). 
Effect of Terminalia arjuna (ethanolic extract) on liver kidney and pancreas histopathology.

In the normal liver tissue section shows sinusoidal cards of hepatocytes with central vein and portal tracts. The portal tracts show portal triad with portal vein, hepatic artery and bile duct, where as the diabetic rat liver tissue section shows distortion in the arrangement of cells around the central vein, periportal fatty infiltration with focal necrosis of hepatocytes (Figure $1 \mathrm{a}$ and b). The bark extract (250 and $500 \mathrm{mg} / \mathrm{kg}$ body weight) treated brought back the cellular arrangement around the central vein and reduced necrosis. Also it helped to bring the blood vessels to normal condition (Figure $1 \mathrm{c}$ and $\mathrm{d}$ ). The group $\mathrm{V}$ and VI did not show any significant change of liver, when compared with group I (figure 1 e and f).

Kidney sections of diabetic rat showed tubular damage, proteinuria and haemorrhage. Haemorrhage is seen with in the Bowman's space due to glomerular damage (Figure $2 \mathrm{a}$ and b). In Terminalia bark extract (250 and $500 \mathrm{mg} / \mathrm{kg}$ body weight) treated diabetic kidney, the damaged capillary loops with increase in the thickness of the wall, glomeruli and tubules without proteinuria and haemorrhage (Figure $2 \mathrm{c}$ and d) Group V and VI did not alter the structure of kidney, when compared with group I (Figure 2 e and f).

The light microscropic examination by specific staining of pancreas in normal tissues section shows lobules of exocrine acini, interlobular ducts and occasional islets of langerhan which is not observed in alloxan induced diabetic pancreas (Figure 3 a \& b). In T.arjuna bark extact (250 and 500mg body weight) treated pancreas the cells seem to have gathered together and small preserved islets similar to the normal (Figure $3 \mathrm{c}$ and d). The group V \& VI did not shows any significant change of pancreas, when compared with normal pancreas (Figure $3 \mathrm{e}$ and $\mathrm{f}$ ).

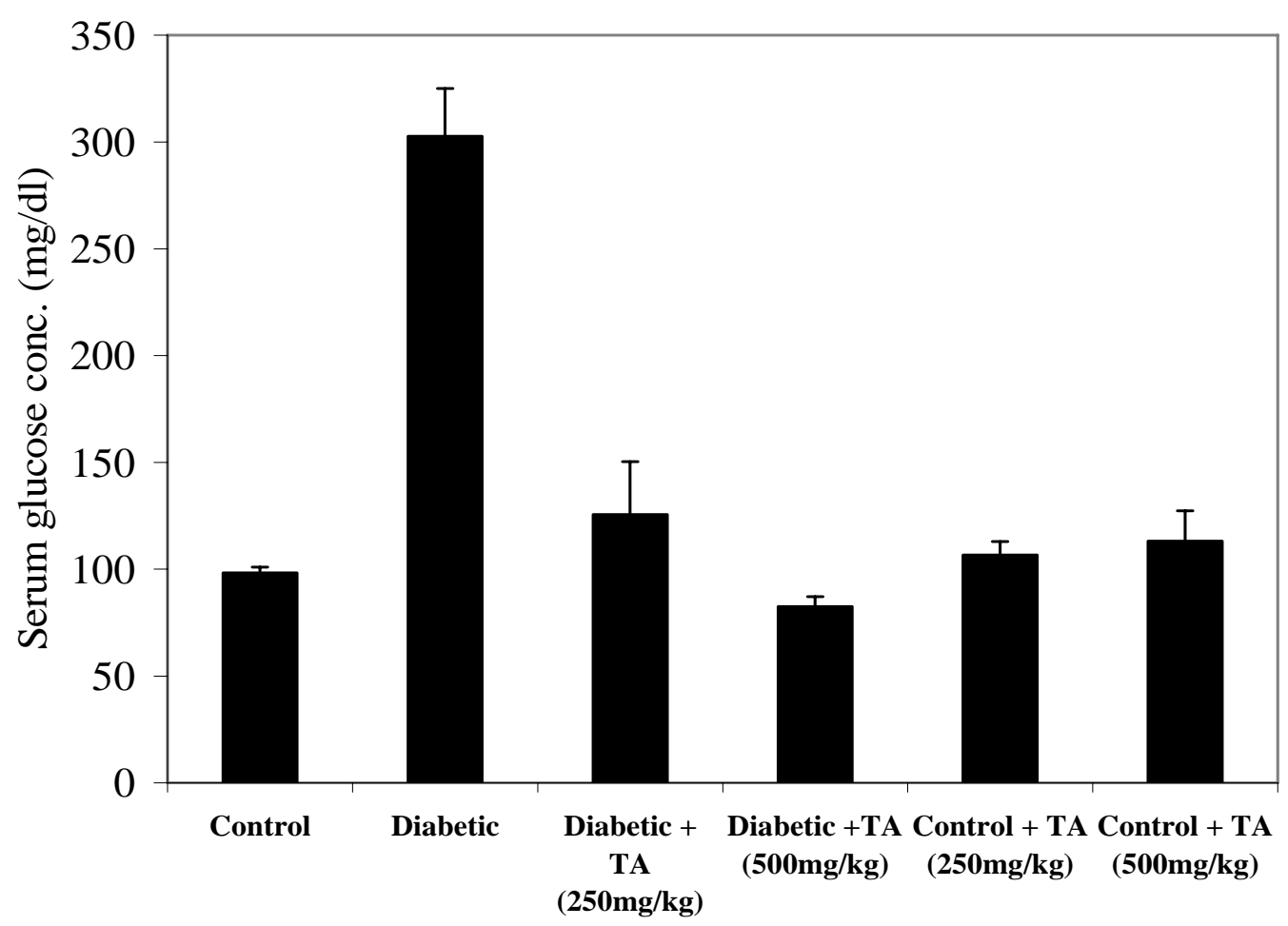

Fig. 1.

Effect of Terminalia arjuna stem bark on serum glucose in alloxan-induced diabetic rats 

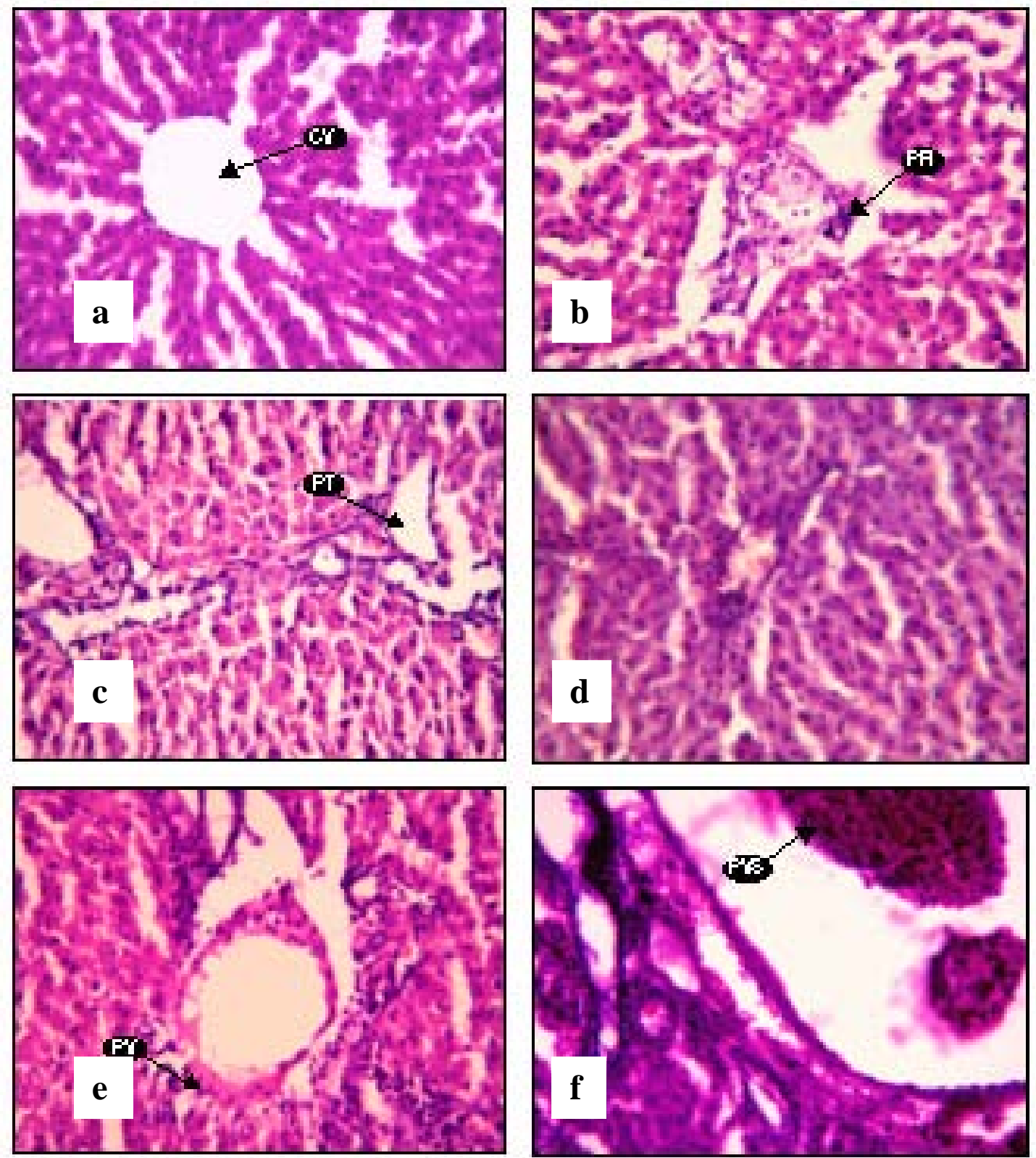

Plate 1

Histopathological Changes in Liver of Control and Experimental rats. a. Group I - Normal liver showing the central vein (CV)with radiating cords of hepatocytes; b.Group II - Diabetic liver shows periportal fatty infiltration (PFI) with focal fat necrosis; c. Group III - Shows normal portal tract (PT) ; d. Group IV Portal track showing normal features; e. Group V - Congested and edematous portal vein (PV) with mild haemorrhage; f. Group VI -Portal vein shows haemorrhage in the lumen in the perivenular space (PVS) 

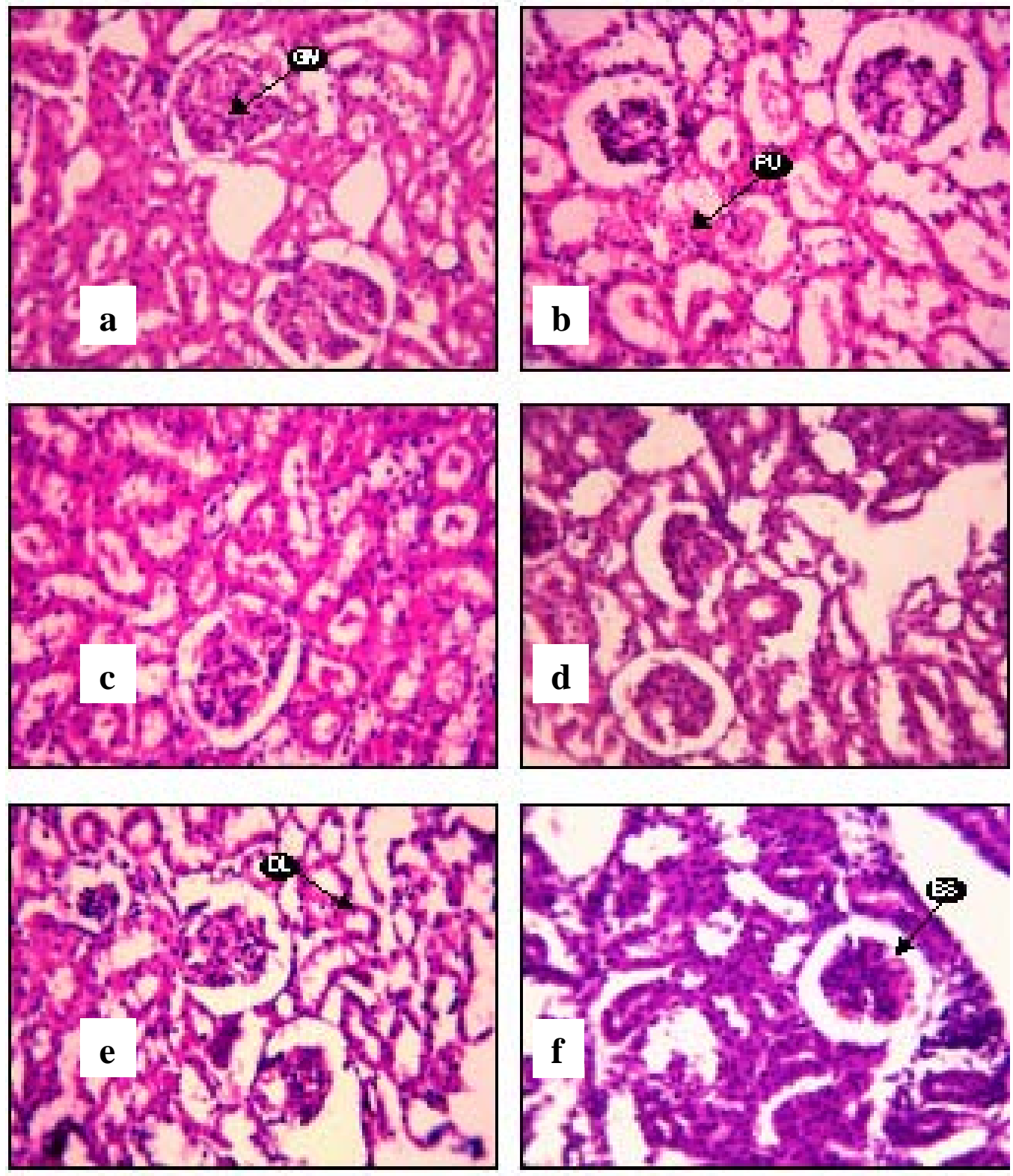

\section{Plate 2}

Histopathological Changes in Kidney of Control and experimental rats. Normal rat kidney show glomeruli (GM) and proximal convoluted tubules. b. Group II shows tubular damage proteinuria (PU) and hemorrhage; c. Group III tubules show proteinuria and glomerular damage; d. Group IV - Shows glomeruli and tubules without proteinuria and haemorrhage; e. Group V-Glomerulus shows some dilated loops (DL) and suffused RBCs; f. Group VI - Glomerulus shows suffused capillary loops with RBCs and expansion by red cells spillage in to Bowman's space (BS) 

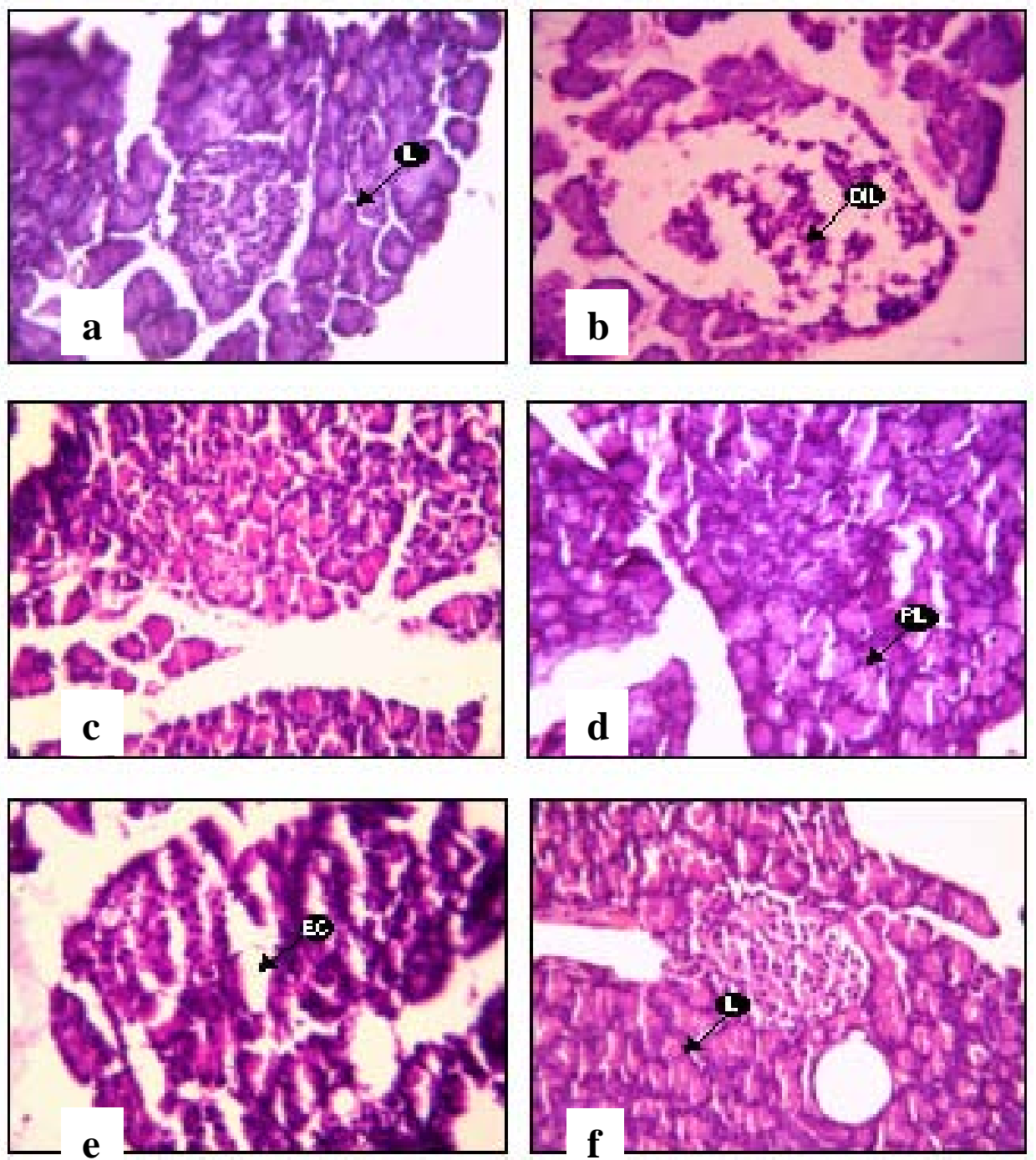

Figure 3

Histopathological Changes Of Pancreas Of Control and experimental Rats. a. Group I - Pancreas showing exocrine acini and endocrine islets (IL); b. Group II - Shows depleted islets (DIL); c. Group III - Shows exocrine acini and small preserved islets; d. Group IV - Shows preserved islets (PIL); e. Group V- Preserved islets and exocrine (EC) are seen; f. Group VI - Pancreas showing islets (IL)

\section{DISCUSSION}

Our findings reveal that the significant decrease of serum glucose level in extract treated diabetic rats. Alloxan not only destroys the pancreatic $\beta$-cells but causes kidney damage, which is however reversible, while streptozotocin selectively destroys pancreatic insulin secreting $\beta$-cells (Gilman et al.,1990). The degenerative changes in the histology of liver and kidney brought about by alloxan administration are similar to earlier observations (Shanmugasundarm et al., 1983, Leegwates et al., 1984, Ghosh et al., 2001 and Thakran et al., 2004). Histologically, liver section of alloxan induced diabetic rats showed marked structural alterations in the liver as a result of absence of insulin. The major alteration was periportal fatty infliteration, necrosis of hepatocytes. This damage is partially reversed by the T.arjuna bark extract treatment and is similar to that observed by Gymnema sylvestre therapy in alloxan diabetic 
rabbits by Shanmugasundaram et al(1983) and Vinca rosea extract in alloxan- induced diabetic rats by Ghosh et al.( 2001). The kidney histopathology data of alloxan induced diabetic rats showed marked tubular damage, haemorrhage in the Bowman's space due to glomerular damage. The results indicate a primary and a secondary effect of the diabetic state on the kidney of the rat. The primary effect, the diabetes factor was associated with hyperglycaemia and was responsible for dilatation of proximal and distal tubules in the cortex. The secondary effect, named the individual response factor, was associated with inflammatory processes (Leegwates et al., 1984). Diuresis is a common feature associated with diabetes which may be the reason for structural changes observed with glomerulus (Das et al., 1996). The excellent recovery of renal function expected with treatment of $T$. arjuna can be explained by the regenerative capability of the renal tubules. Similar results have been observed with the treatment of alloxan induced diabetic rats with Trigonella foenum graecum seed powder by Thakran et al. (2004). The role of T.arjuna in reversing the diabetic state at the cellular level besides the metabolic normalization further proves its potential as an antidiabetic assert.

The present study revealed that the immediate action of alloxan induced diabetes by destroying $\beta$ cells even at a single dose of $120 \mathrm{mg} / \mathrm{kg}$ of body weight. The ultra structure of alloxan diabetic pancreas showed considerable reduction in the islet langerhans and depleted islets. These are in agreement with earlier reports (Gholamali et al., 2005 and Ghosh et al., 2001). The diabetic rats showed pancreatic islet regeneration. The regenerative effect of the pancreatic cells by Terminalia arjuna via exocrine cells of pancreas may enlighten the positive effects of these agent on the production of insulin.

\section{Conclusion}

The goal of these studies was to evaluate the effect of Terminalia arjuna (50\% ethanolic extract) on development of liver, kidney and pancreatic tissue damage or complications in alloxan - induced diabetic rats. Our data show that the Terminalia arjuna extract was found to effectively improve the liver, kidney and pancreas function and reduced the lesions associated with diabetic state in alloxan diabetic rats. Further more, the effect of oral $T$. arjuna at the dose $500 \mathrm{mg} / \mathrm{kg}$ body weight was more efficacy than $250 \mathrm{mg} / \mathrm{kg}$ body weight.

\section{REFERENCES}

Das A.V., Padayatti P.S and Paulose C.S. (1996): Effect of leaf extract of Aegle marmelose (L.) Correa ex Roxb. On histological and ultrastructural changes in tissues of streptozotocin induced diabetic rats. Indian J. Exp. Biol., 34, 341-345.

Dunn W.L. (1974): Hand book of histopathological and histochemical techniques. Third Edition, Redwood, Burn, Ltd., Trowbridge and Esher.

Gholamali A.T., Maleki M., Matudayen M.H and Sines S. (2005): Effect of fenugreek, onion and garlic on blood glucose and histopathology of pancreas of alloxan-induced diabetes rat. Indian J. Med. Sci., 59(2), 64 - 69.

Ghosh S and Surawanshi S.A.(2001) : Effect of Vinca rosea extracts in treatment of alloxan diabetes in male albina rats. Indian J. Exp. Biol., 8, 748 - 759 Gilman A.G. (1990), Goodman and Gilman's the pharmacological basis of therapeutics, Pergamon Press, New York, $8^{\text {th }}$ edn, 1317- 1322.

Giorgino F, Lavida L, Cavallo P.P., Scolinica B, Fuller J, and Chaturvedi N. (2004): Factor associated with progression to macroalbuminuria in microalbuminuria type 1 patients : Eurodiab prospective and complication study. Diabetologia. 4, $1413-1418$.

Keith G. Tolman, M.D., Fonseca A.V., Meng H., Tan and Dalpiaz A. (2004) : Narrative Review. Hepatobiliary disease in type 2 diabetes mellitus. Annals of Internal Medicine, 12, 141, 946 - 952.

Khanna A.K., Rameshchander and Kapoor N.L. (1996): Terminalia arjuna an ayurvedic cardiotonic regulates lipid metabolism. Phytotherapy, 10, 663 665.

Leegwates D.C and Kuper C.F. (1984): Evaluation of histological changes in the kidneys of the alloxan diabetic rat by means of factor analysis. Food Chem. Toxicol., 22(7), 551 - 557.

Pathak S.R., Upadhyay L., Singh R.H., Dubey G.P and Udupa K.N. (1990): Effect of T.arjuna on autocodial and lipid profiles of rabbits. Indian drugs, 27, 221-227. 
Perfumi $M$ and Tacconi R. (1996) : Antihyperglycemic effect of fresh Opuntiadillenii fruit from Tenerife (Canry islands). Indian J. Pharmacol., 34, 41.

Purohi S.S and Vyas S.P. (2004) : Medicinal Plant Cultivation. A Scientific Approach Agrobios (India) Edn., 76, 525 - 527.

Ram A., Lauria P., Gupta R.P., Kumar P and Pandsharma V.N. (1997) : Hypocholesterolemic effects of T.arjuna tree bark. J. Ethnopharmacol., 55, 165-169

Ravivijayavargia, Monikakumar and Gupta S. (2003): Hypoglycemic effect of aqueous extract of Enicostemma littoral Blume (Chhotachirayata) on alloxan induced diabetes mellitus in rats, Indian $\mathrm{J}$. Exp. Biol., 8, 781-784.

Shaila, H.P., Udupa, S.L and Udupa, A.L. (1997a), Hypolipidemic effect of Terminalia arjuna in cholesterol fed rabbits, Fitoterapia, 68, 405 - 409

Shanmugasundaram K.R., Panneerselvam C.E.,
Samudram $P$ and Shanmuga sundaram E.R.B. (1983): Enzyme changes and glucose utilization in diabetic rabbits : The effect of Gymnema sylvestre. R. Br. J. Ethnopharmacol., 7, 205 - 234.

Thakran S., Siddiqui M.R., Baquer N.Z. (2004): Trigonella foenum graecum seed powder protects against histopathological abnormalities in tissues of diabetic rats. Mol Cell Biochem., 266 (1-2), 151159.

Tiwari A.K., Gode J.D and Dubey G.P. (1989): Effect of T.arjuna bark powder on serum lipids and lipoproteins in hypercholesterolemic rabbits. Indian Drugs, 26, 664.

Trinder P. (1969): Glucose oxidase method. Ann. Clin. Biochem., 6, 24 